\title{
ANATOMIA FOLIAR DE RUDGEA DECIPIENS MÜLL. ARG. E R. MACROPHYLLA BENTH. (RUBIACEAE) ${ }^{1}$
}

\author{
André Mantovani ${ }^{2,3}$ \\ Mario Gomes ${ }^{2}$ \\ Doria Maria Saiter Gomes ${ }^{2}$ \\ Ricardo Cardoso Vieira ${ }^{2}$ \\ Recebido em 04.08.91. Aceito em 29.09.95.
}

\begin{abstract}
RESUMO: (Anatomia foliar de Rudgea decipiens Müll.Arg. e $R$. macroplyylla Benth. [Rubiaceae]). São apresentados dados sobre a anatomia das folhas de Rudgea decipiens e R. macrophylla (Rubiaceae). Ambas ocorrem na Floresta de Tijuca (Mata Atlântica), Rio de Janeiro. As folhas são hipostomáticas, com estômatos do tipo paralelocítico, dotadas de mesofilo dorsiventral, feixes vasculares do tipo colateral, papilas na epiderme abaxial e cutícula estriada. Em R. macrophylla, destaca-se a ocorrência de estômatos peculiares.
\end{abstract}

Palavras-chave: Anatomia foliar, Rudgea, Rubiaceae.

ABSTRACT: (Leaf anatomy of Rudgea decipiens Müll.Arg. and R. macrophylla Benth. [Rubiaceae]). Anatomical characteristics of Rudgea decipiens and $R$. macroplyylla leaves were examined. The two species grow in Floresta da Tijuca (Mata Atlântica), Rio de Janeiro municipality. The leaves are hipostomatics, with parallelocytic stomata, dorsiventral mesophyll, colateral vascular bundles, papillae on the lower surface and striate cuticle. The stomata show peculiar aspects in $R$.
macrophylla.

Key words: Leaf anatomy, Rudgea, Rubiaceae.

\section{Introdução}

A Mata Atlântica compreende hoje um dos ecossistemas mais ameaçados do país, face à crescente ação antrópica de que é alvo.

O Parque Nacional da Tijuca, que encerra um grande número de espécies, constituindo um dos mais importantes remanescentes de Mata Atlântica do Rio de Janeiro.

1 Apoio FUJB.

2 Departamento de Botânica, Instituto de Biologia, CCS, UFRJ, Bloco A, Ilha do Fundão, Cidade Universitária, 21.949-900, Rio de Janeiro, RJ, Brasil.

${ }^{3}$ Bolsista de Iniciação Científica do CNPq. 
Tendo em vista a progressiva devastação desta região fitogeográfica e que dados anatômicos sobre esta vegetação são pouco numerosos, torna-se indispensável que a flora deste ecossistema seja estudada detalhadamente, sobretudo do ponto de vista estrutural.

A Mata Atlântica é composta por numerosas famílias botânicas, destacando-se entre elas as Rubiaceae, com cerca de 10700 espécies subordinadas a aproximadamente 637 gêneros (Robbrecht 1988).

Entre os representantes de Rubiaceae ocorrentes na Floresta da Tijuca, figura o gênero Rudgea, com cerca de 165 espécies, distribuídas pelo México, Antilhas, América Central e do Sul (Steyermark 1974).

Na pesquisa bibliográfica, destacam-se os trabalhos de Accorsi $(1947,1949)$ e Pant \& Mehra (1965), referentes aos estômatos e características morfo-anatômicas e citológicas da epiderme inferior de várias espécies da família Rubiaceae. Barros (1959) relata a ocorrência de domácias em mais de 600 espécies da família em questão, assim como Lersten (1974), faz referência à morfologia e distribuição de coléteres e cristais.

Com o objetivo de contribuir para o conhecimento anatômico da família Rubiaceae, os autores realizaram o estudo de Rudgea decipiens Mull. Arg. e Rudgea macrophylla Benth. que representa o quinto trabalho sobre a família em questão (Vieira 1986; Vieira 1986/1988; Vieira et al. 1993 e Gomes et al. 1995).

Neste trabalho são discutidos aspectos da anatomia foliar das espécies acima referidas, visando adicionar informações ao trabalho do anatomista, assim como correlacionar estes aspectos ao habitat onde vivem.

\section{Material e métodos}

O material utilizado no presente estudo é proveniente da floresta da Tijuca (Mata Atlântica, município do Rio de Janeiro). Rudgea decipiens foi coletada na mata do Jardim Botânico, próximo à caixa-d'água, enquanto $R$. macrophylla foi coletada na estrada D.Castorina, Km 2. As exsicatas de Rudgea decipiens e R. Macrophylla foram depositadas no Herbário do JBRJ sob os números RB 296.732 e RB 276.503, respectivamente.

A distribuição da temperatura média anual da Floresta da Tijuca apresenta uma amplitude de variação em torno de $6^{\circ} \mathrm{C}$, situando-se entre $25^{\circ} \mathrm{C}$ em fevereiro e $19^{\circ} \mathrm{C}$ em julho. A média das máximas alcança os $32^{\circ} \mathrm{C}$ no verão, ficando a média das mínimas em torno dos $12^{\circ} \mathrm{C}$ no inverno. A pluviosidade é bem distribuída ao longo do ano, com média anual acima dos $2000 \mathrm{~mm}$ (Vieira 1990). A umidade relativa do ar é bastante regular, com média anual de $82 \%$ (Mattos et al. 1976).

Para análise anatômica, foram coletadas folhas de sombra provenientes do 4 nó, e fixadas em etanol $70^{\circ} \mathrm{GL}$. Secções transversais à mão livre foram obtidas ao nível do bordo, região intercostal, nervura principal e pecíolo, sendo posteriormente coradas pelo safrablau (Bukatsch 1972).

Para o estudo das epidermes em vista frontal foram retirados pequenos retângulos do terço médio da lâmina foliar, procedendo-se a dissociação pelo método de 
Jeffrey (Johansen 1940). Devido a presença de uma densa cobertura de cera nas epidermes de $R$. macrophylla, os fragmentos foram fervidos durante 10 minutos em clorofórmio com o objetivo de retirar a cera, e posteriormente submetidos à mistura de Jeffrey (Johansen 1940). A determinação do número de estômatos por $\mathrm{mm}^{2}$ foi feita pela projeção de um campo correspondente a um quadrado de $1 \mathrm{~mm}$ de lado, calculando-se a média aritmética de 25 campos. Os estômatos foram classificados de acordo com Metcalfe \& Chalk (1950) e Payne (1970).

Para observações da organização da rede de nervuras, a folha foi diafanizada e corada de acordo com as recomendações de Strittmater (1973) e o padrão de venação foi classificado segundo Hickey (1974).

Para alguns testes histoquímicos foram utilizados cortes à mão livre de material vivo, submetidos a reagentes específicos. As substâncias tanóides foram testadas pelo reagente de Hoepfner-Vorsatz (Reeve 1951), o amido pelo lugol e substâncias lipídicas pelo Sudan IV (Johansen 1940).

Cristais de oxalato de cálcio foram reconhecidos pela solubilidade em ácido clorídrico (Strasburguer 1986). Os desenhos foram realizados com auxílio de câmara clara acoplada ao microscópio binocular Zeiss e as escalas projetadas com a mesma combinação ótica. Os diagramas seguiram a orientação de Metcalfe \& Chalk (1950).

\section{Resultados}

Descrição morfológica

Rudgea decipiens Müll. Arg.

Arbusto com aproximadamente $20 \mathrm{~cm}$ de altura; ramos pálidos, cilíndricos, ao longo dos quais as vezes são encontradas estípulas crustáceas persistentes; estípulas arredondadas com acúleos no dorso. Folhas oblongas ou obovadas com 2-5 x 1 a 2,5 $\mathrm{cm}$., com base estreita obtusa ou subcordada, padrão de venação broquidódromo (Figura 1).

$R$. decipiens é a espécie de menor porte do gênero, ocupando o estrato mais baixo da mata, onde há pouca luminosidade. No entanto, os ramos apresentam uma torção em que suas folhas tenham uma posição quase horizontal, de modo a melhor absorver a pouca quantidade de luz que nelas chega.

\section{Rudgea macrophylla Benth.}

Arbusto com até $3 \mathrm{~m}$ de altura; ramos longos, crassos, suberosos, estriados, tortuosos; estípulas ovadas, partidas no ápice, com numerosos acúleos no dorso. Folhas aglomeradas no ápice dos ramos, com pecíolos crassos, com até $1,5 \mathrm{~cm}$ de comprimento; limbo amplo, elíptico ou obovado-lanceolado, de base truncada a subcordada e ápice agudo, com 20-40 x 6-20 cm., padrão de venação broquidódromo (Figura 4). 

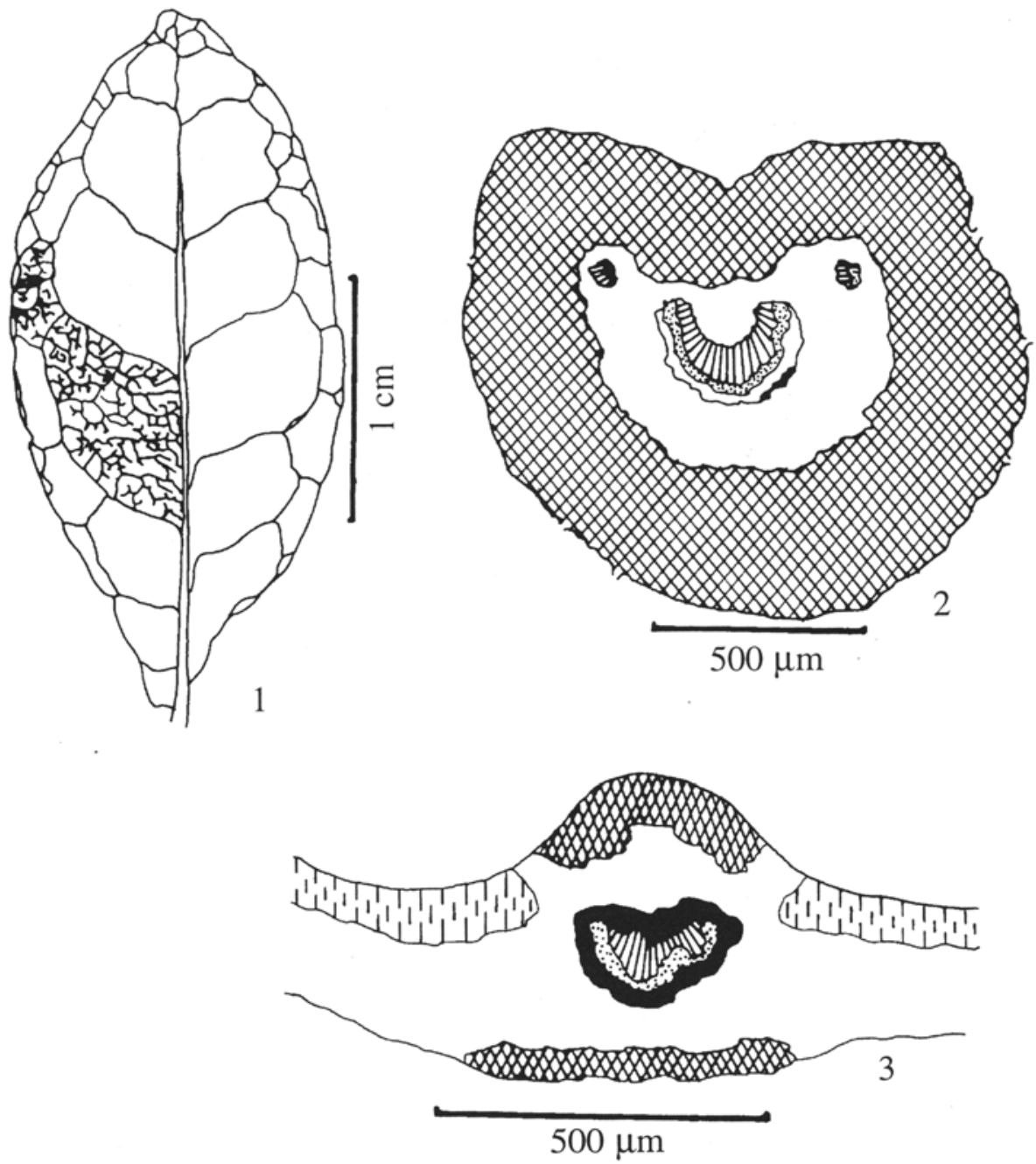

Figuras 1 a 3. Folha de R. decipiens. 1. Aspecto geral, evidenciando padrão de venação broquidódromo. 2 . Diagrama do pecíolo na região mediana, mostrando feixe vascular na forma de arco. 3. Diagrama da nervura principal ao nível mediano, mostrando feixe vascular envolvido por um anel de fibras.

R. macrophylla é uma espécie de fácil reconhecimento, principalmente por possuir ramos crassos, folhas amplas e inflorescências em tirsos ovóides, quase capitados. Suas folhas, aglomeradas no ápice dos ramos, fazem acumular grande quantidade de matéria orgânica, caída das árvores, que pesa e encurva os ramos. 

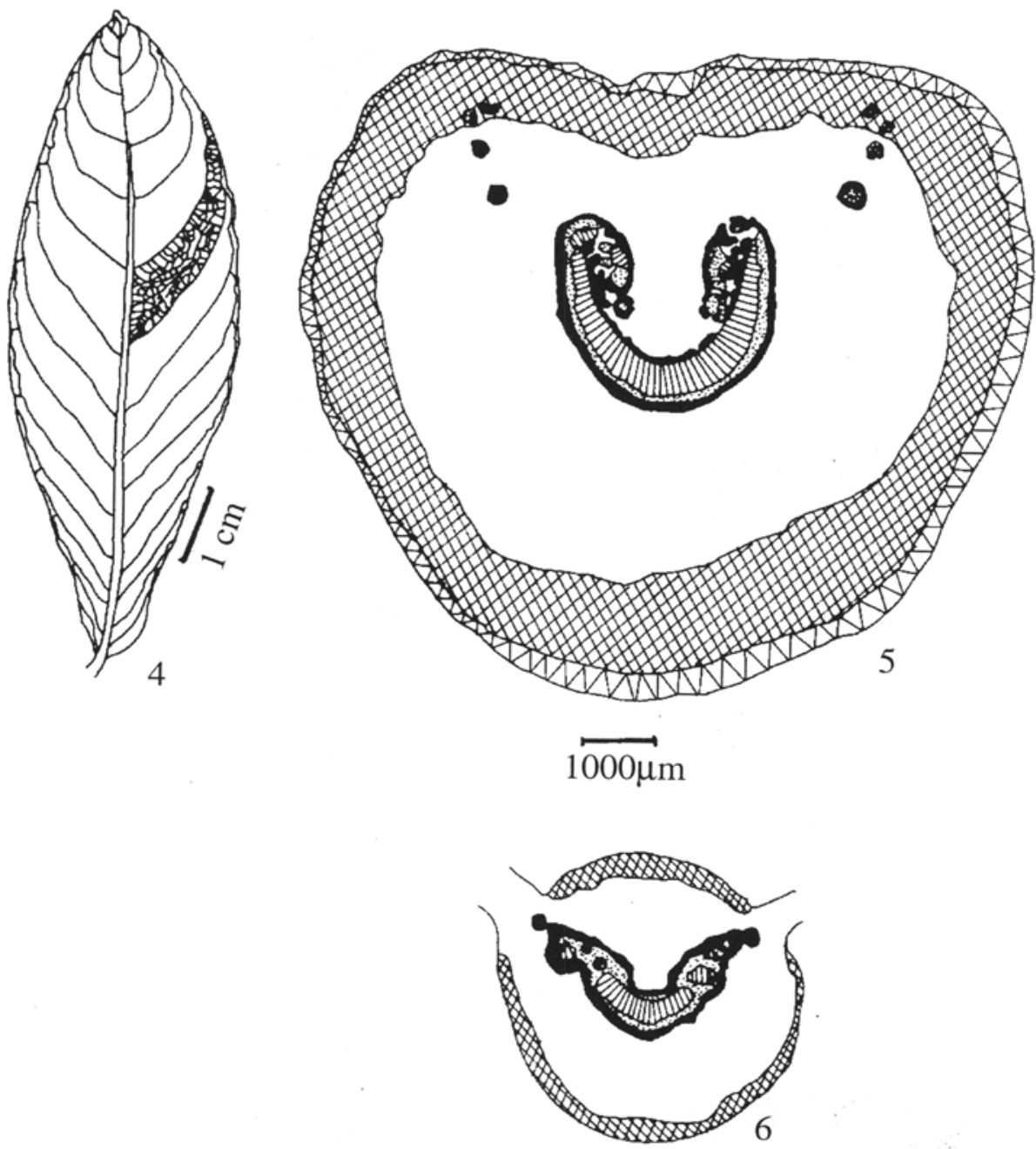

Figuras 4 a 6 . Folha de $R$. macrophylla. 4. Aspecto geral, evidenciando padrão de venação broquidódromo. 5. Diagrama da região mediana do pecíolo, evidenciando feixe vascular principal, feixes adicionais e periderme. 6. Diagrama da nervura principal ao nível mediano, mostrando feixe vascular envolvido por um anel de fibras.

\section{Descrição anatômica}

O pecíolo das espécies em estudo, em secção transversal, possui formato planoconvexo (Figuras 2 e 5), sendo levemente sulcado na face adaxial em Rudgea decipiens (Figura 2). O sistema vascular apresenta um feixe central, do tipo colateral, na forma de um arco. Em R. macrophylla (Figura 5), na região correspondente a medula, 

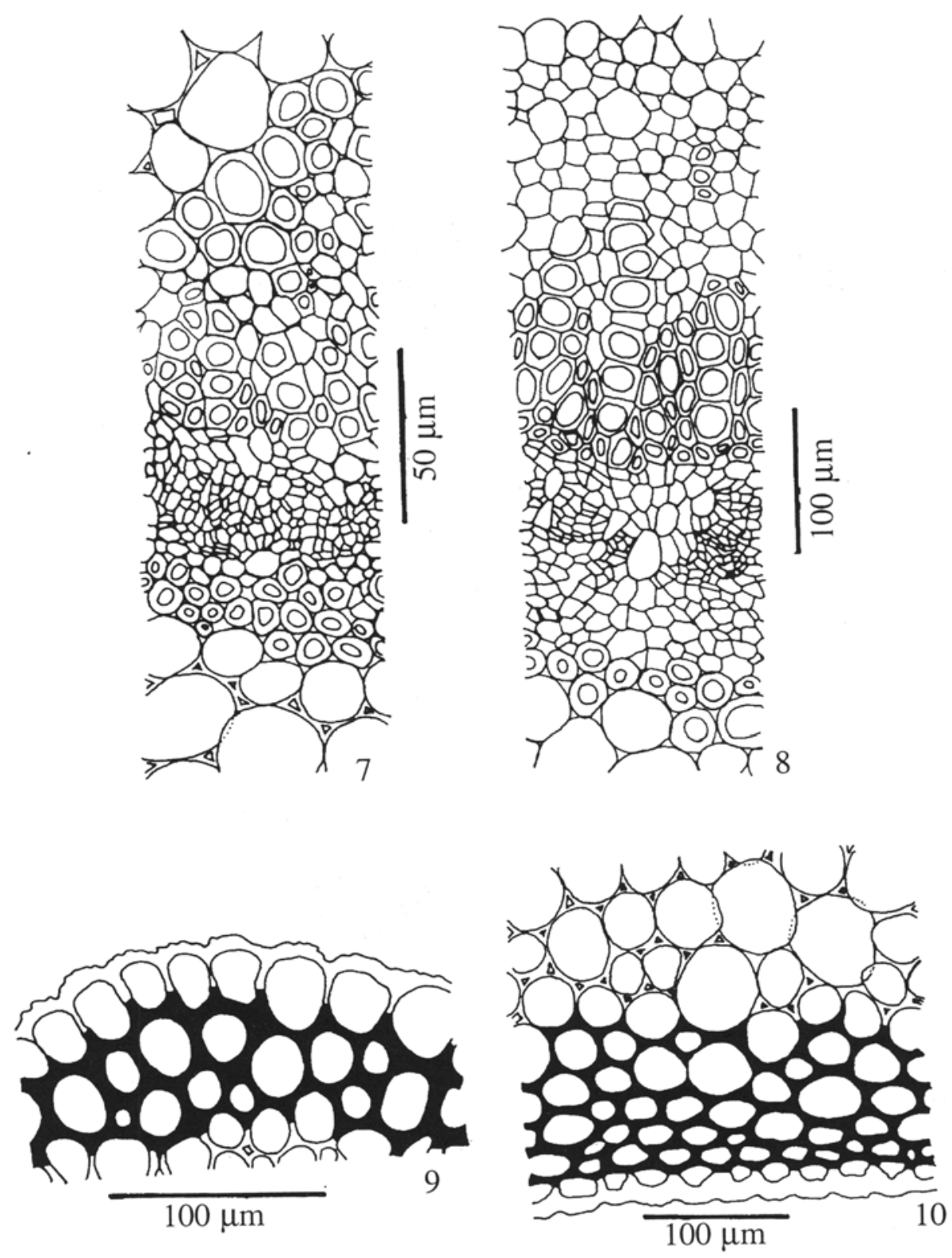

Figuras 7 e 8. Detalhe do feixe vascular na nervura principal de $R$. decipiens (7) e R. macrophylla (8). Figuras 9 e 10. Colênquima angular, ao nível da nervura principal de $R$. decipiens (9) e $R$. macrophylla (10). 

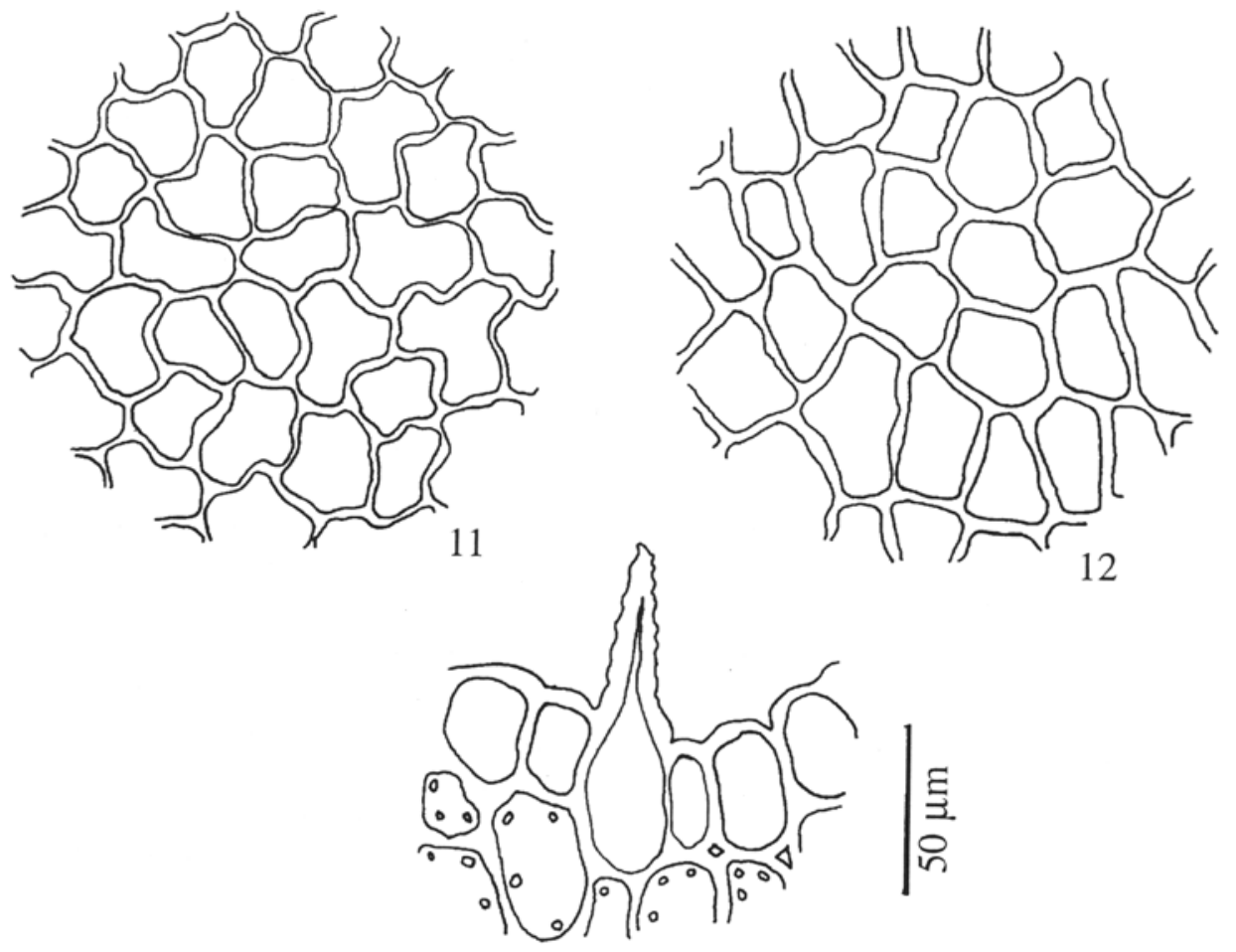

13
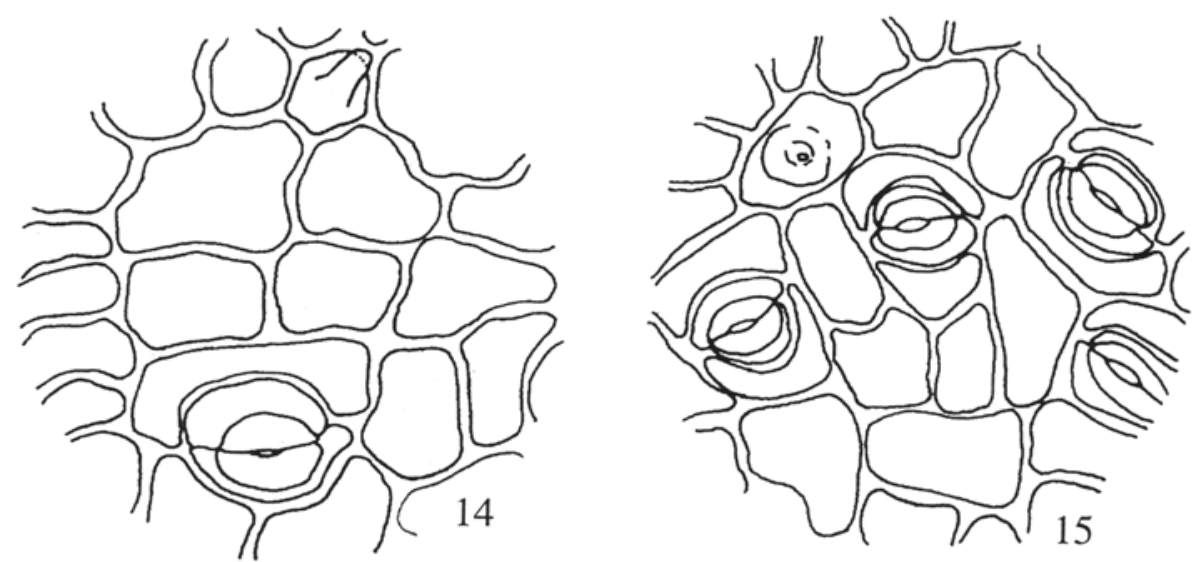

Figuras 11 a 15. Epidermes foliares. 11 e 14. Epiderme adaxial e abaxial de $R$. decipiens, respectivamente. 13. Detalhe da papila de $R$. decipiens. 12 e 15 . Epiderme adaxial e abaxial de $R$. macrophylla, respectivamente. 
observa-se que as extremidades desse feixe sofrem fragmentação, originando pequenos grupos de xilema e floema sem organização definida. Feixes menores, localizados lateralmente, acompanham o feixe central, sendo em número de $2 \mathrm{em} R$. decipiens $\mathrm{e}$ variando de 7-8 em $R$. macrophylla (Figura 2 e 5).

No terço médio da lâmina foliar, a organização do sistema vascular da nervura principal reflete a do pecíolo (Figuras 3,6,7 e 8). Em R. macrophylla (Figura 6), o xilema apresenta-se fragmentado, porém completamente envolvido pelo tecido floemático. A partir do terço basal pequenos feixes se destacam da nervura principal, a fim de constituírem as nervuras de pequeno e médio porte.

O sistema de sustentação está representado por colênquima, fibras e esclereídeos. O colênquima, do tipo angular (Figuras 9 e 10), ocorre ao longo de toda a folha. No pecíolo, está formado por 5-6 estratos de células em $R$. decipiens e por 10-15 estratos em $R$. macrophylla. Na lâmina foliar, o colênquima é observado nas faces adaxial e abaxial da nervura principal (Figuras 3 e 6), e no bordo de $R$. macrophylla (Figura 25). As fibras localizam-se somente na região perivascular. No pecíolo, ocorrem como pequenos feixes junto ao floema de $R$. decipiens (Figura 2), e como um anel descontínuo em $R$. macrophylla (Figura 5). Já na nervura principal as fibras envolvem completamente o sistema vascular de ambas as espécies (Figuras 3 e 6). Em R. decipiens, nas regiões proximal e mediana do pecíolo, os elementos parenquimáticos junto ao floema possuem menores dimensões e paredes mais espessas, sendo substituídos por fibras a partir da região distal (Figura 2). Quanto aos esclereídeos, distribuem-se na região cortical do pecíolo, parênquima fundamental da nervura principal e no bordo de $R$. macrophylla (Figura 25).

O sistema de revestimento está representado pela periderme e epiderme.

A periderme ocorre somente no pecíolo de $R$. macrophylla (Figura 5) e está constituída por células tabulares, dispostas em séries radiais. Caracteriza-se por formar um anel contínuo nas regiões proximal e mediana, fato porém, não observado na região distal. Nesta, o carácter contínuo da periderme se restringe a face superior, enquanto que na inferior ela se apresenta em pequenos grupos separados, vindo a desaparecer por completo em ambas as faces, ao nível do terço basal da lâmina foliar.

As epidermes de ambas as espécies, em vista frontal, revelam células de formato poligonal (Figuras 11,12,14 e 15). As paredes anticlinais são levemente sinuosas na face adaxial e retas na face abaxial de R. decipiens (Figuras 11 e 12). Em R. macrophylla, ambas as epidermes apresentam células com paredes retas (Figuras 14 e 15). Nas duas espécies, a cutícula da superfície adaxial apresenta ornamentações na forma de estrias, assim como na superfície abaxial de $R$. macrophylla. Em secção transversal, as epidermes mostram-se uniestratificadas (Figuras 22 e 23).

Na epiderme abaxial, verifica-se a presença de papilas, com formato de pequenos cones, caracterizadas pela projeção da parede periclinal externa, acompanhada pelo lume celular (Figura 13). Tais estruturas ocorrem numa concentração média de $32 / \mathrm{mm}^{2}$ em $R$. decipiens e $5 / \mathrm{mm}^{2}$ em $R$. macrophylla.

Os estômatos ocorrem somente na face abaxial (folha hipoestomática), no número médio de $38 / \mathrm{mm}^{2}$ em $R$. decipiens e $130 / \mathrm{mm}^{2}$ em $R$. macrophylla. São predo- 
minantemente do tipo paralelocítico, caracterizados pela ocorrência de três ou mais células anexas de diferentes tamanhos (Figuras 14 e 15). Em R. macrophylla observou-se complexos estomáticos que se diferenciam do tipo padrão. Em alguns casos, as células anexas são semelhantes aos demais elementos epidérmicos, cujo número pode variar de 2-4 células dispostas de modo paralelo ou não às células estomáticas (Figuras 16 e 17). Nestes casos, as demais células epidérmicas organizam-se concentricamente ao estômato. Por outro lado, modificações ocorrem com frequência nas células estomáticas. Estas podem não se diferenciar claramente das células anexas (Figura 18). Além disso, as paredes que flanqueiam o poro são mais espessadas. Complexos estomáticos que não completaram sua diferenciação encontram-se dispersos pela epiderme abaxial (Figura 19).

Secções transversais na região mediana do estômato paralelocítico revelam que as células estomáticas situam-se no mesmo nível das demais células epidérmicas (Figuras 20 e 21). As paredes periclinais externa e interna são espessadas, observando-se, na primeira, a formação de duas saliências cutinizadas que delimitam o átrio externo ao ostíolo.

O mesofilo está constituído pelo parênquima assimilador, que se diferencia em paliçádico e lacunoso (Figuras 22-25). O parênquima paliçádico é formado por um único estrato celular junto a epiderme adaxial, caracterizando desta maneira o tipo de folha dorsiventral (Figuras 22 e 23). O parênquima lacunoso é constituído por várias camadas de células de paredes delgadas, frouxamente dispostas, originando grandes espaços intercelulares. Em $R$. decipiens (Figura 22), este parênquima é formado por 3-4 estratos, enquanto em $R$. macrophylla apresenta 11-12 (Figura 23).

O bordo foliar mostra-se ligeiramente fletido em direção a face abaxial (Figuras 24 e 25). A epiderme é uniestratificada, recoberta por cutícula espessa, que em $R$. macrophylla, apresenta reentrâncias, alcançando a parede periclinal externa (Figura 25 ). As células do parênquima assimilador diminuem de tamanho e atingem a extremidade do bordo em $R$. decipiens (Figura 24). Em $R$. macrophylla, esta região é ocupada pelo colênquima e esclereídeos solitários. (Figura 25).

Idioblastos contendo cristais de oxalato de cálcio são encontrados em ambas as espécies. O tipo ráfide ocorre tanto no pecíolo, quanto na lâmina foliar das espécies em questão (Figura 23). As drusas estão restritas à lâmina foliar de $R$. decipiens (Figura 22), enquanto que cristais prismáticos diminutos estão distribuídos no parênquima cortical do pecíolo e parênquima paliçádico de $R$. macrophylla_(Figura 23).

Pequenas gotas de gordura foram observadas no parênquima assimilador da lâmina foliar, na região cortical do pecíolo e nas epidermes de ambas as espécies, bem como na periderme de $R$. macrophylla. tivos.

Teste para identificação de substâncias tanóides forneceram resultados nega-

\section{Discussão}

O estudo da anatomia da folha de $R$. decipiens e $R$. macrophylla revelou que sua organização reflete as características gerais citadas por Solereder (1908) para a família Rubiaceae. 

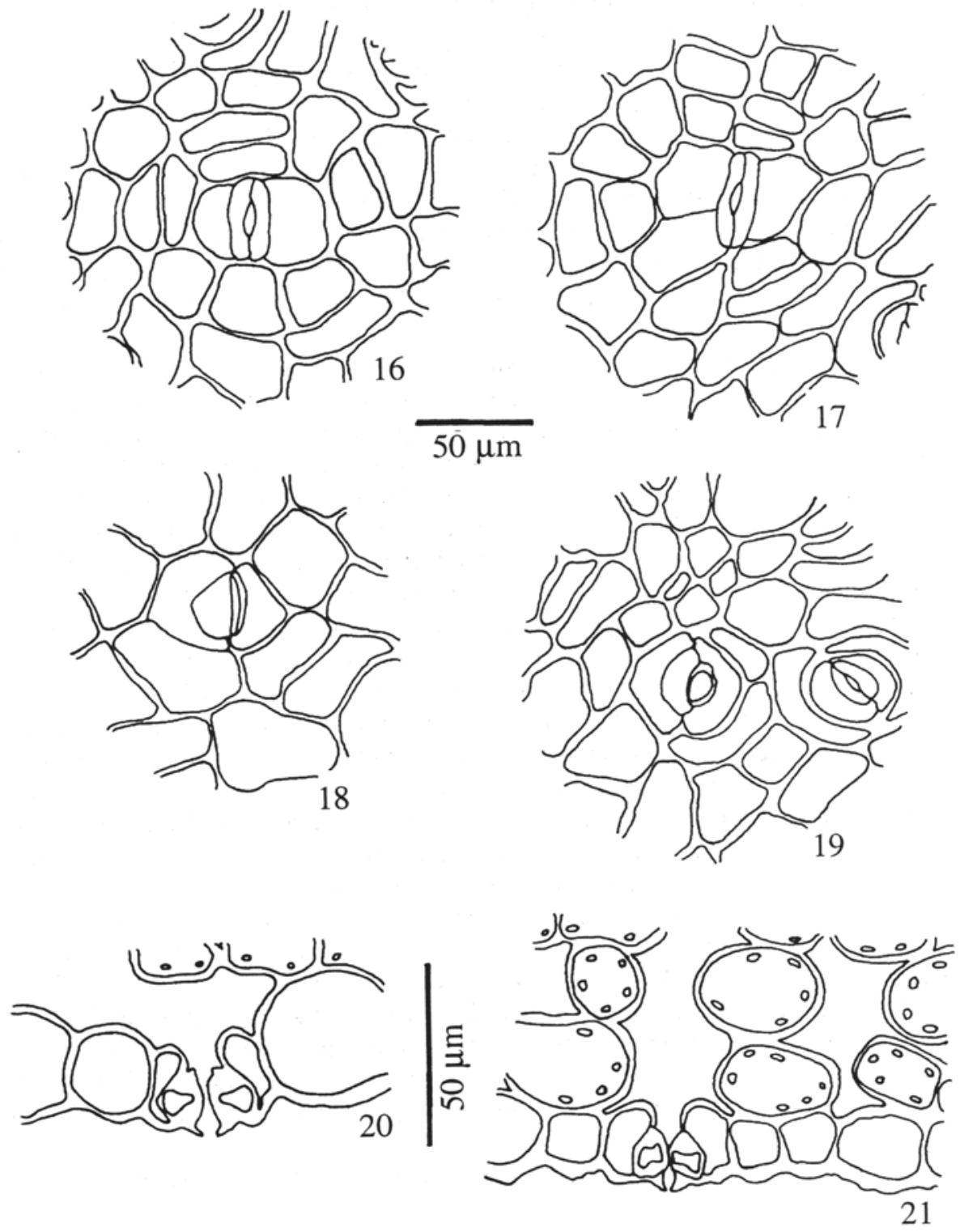

Figuras 16 a 19. Epiderme abaxial de $R$. macrophylla, evidenciando complexos estomáticos que se diferenciam do tipo padrão.

Figuras 20 e 21 - Secção transversal, ao nível equatorial, das células estomáticas de $R$. decipiens (20) e $R$. macrophylla (21). 

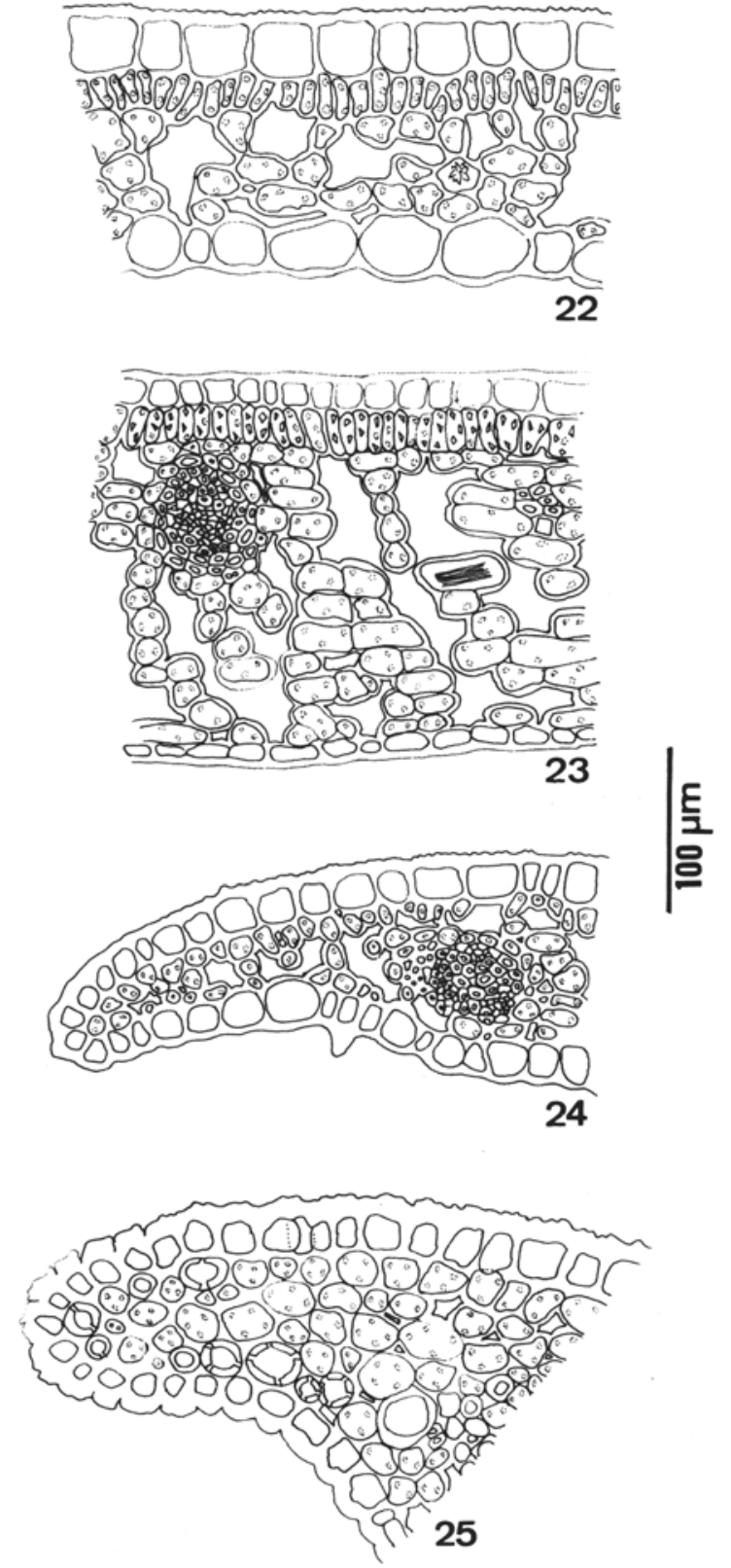

Figuras 22 e 23- Detalhe do mesofilo de $R$. decipiens (22) evidenciando a presença de drusas, e $R$. macrophylla (23) mostrando ráfides e diminutos cristais prismáticos.

Figuras 24 e 25 - Secção transversal do bordo de $R$. decipiens (24) e $R$. macrophylla (25), mostrando a presença de esclereídeos em $R$. macrophylla. 
O sistema vascular do pecíolo, constituído de feixe central sob a forma de arco, podendo ou não estar acompanhado de feixes adicionais, também foi descrito para quatro espécies de Psychotria da Floresta da Tijuca por Vieira et al. (1993) e Gomes et al. (1995).

Em relação aos tecidos de sustentação, cabe ressaltar a presença de esclereídeos distribuídos na folha de $R$. macrophylla. Tal fato pode ser interpretado no sentido de aumentar a resistência da folha, em decorrência de sua grande dimensão.

O sistema de revestimento das espécies em questão está representado pela periderme e epiderme. Haberlandt (1928) revela que a periderme exerce eficiente proteção contra a perda de água, como isolante térmico, contra herbivoria e contra a entrada de fungos invasores. O acúmulo de material orgânico deciduo na junção do pecíolo com o caule de $R$. macrophylla leva a proliferação de fungos nesta região. Portanto, a presença de uma periderme revestindo o pecíolo pode ser considerada, provavelmente, como um fator de proteção contra fungos, já que $R$. macrophylla vegeta num ambiente que proporciona o estabelecimento de rica flora micológica.

Isanogle (1944), Combes (1946) e Hughes (1959) referem que a sinuosidade das paredes anticlinais das células epidérmicas está diretamente relacionada com o grau de sombreamento. Nas espécies em estudo, as paredes anticlinais são predominantemente retas, apesar das folhas serem sombreadas pelas plantas dos estratos superiores. Tal fato mostra a possibilidade de que outros fatores, além da luz, possam estar influenciando na determinação desse carácter.

A cutícula que reveste a epiderme adaxial de $R$. decipiens e $R$. macrophylla apresenta ornamentações em forma de estrias. Accorsi (1947) registra a presença de estrias na epiderme abaxial de 81 espécies de Rubiaceae. Após analisar 226 espécies de Dicotiledoneas, Dunn et al. (1965) verificaram cutícula enrugada para a maioria das espécies de ambiente xérico e lisa para espécies mesófitos ou higrófitos. Os resultados obtidos no presente estudo não correspondem aos de Dunn et al. (1965), pois as duas espécies ocorrem em ambiente com grande disponibilidade de água.

Stace (1965) afirma que pode haver uma grande variabilidade nos padrões de ornamentação cuticular em algumas espécies, enquanto que em outras esse padrão se mostra mais estável. Neste último caso, o autor confere a esta característica considerável valor taxonômico.

As folhas de $R$. decipiens e $R$. macrophylla apresentam estômatos na face inferior, fato também observado por Vieira et al. (1993) e Gomes et al. (1995) em seus respectivos estudos sobre espécies de Rubiaceae da Mata Atlântica. Coutinho (1962) ressalta o caráter usual do hipoestomatismo em espécies da floresta pluvial tropical. Esse mesmo autor acredita que tal fato possa se constituir numa proteção contra o recobrimento e a obliteração das fendas estomáticas por pequenos musgos, hepáticas, liquens e outros componentes da flora epifílica que, constantemente recobrem a face adaxial de espécies da mata pluvial, tal como observado em $R$. decipiens e $R$. macrophylla.

Os estômatos encontrados nas espécies em estudo são predominantemente do tipo paralelocítico, sendo que a disposição das células anexas coincide com as ob- 
servações de Bahadur et al. (1971) e Morretes (1980), em estudos sobre os estômatos da família Rubiaceae. Entretanto, a análise da epiderme inferior de $R$. macrophylla revelou a existência de complexos estomáticos que fogem do tipo padrão.

Pant \& Mehra (1965), estudando a epiderme de espécies de Rubiaceae, descrevem tipos estomáticos denominados “estruturas anômalas e/ou abortadas", em decorrência de serem originados de anormalidades durante a sua formação. Embora não tenha sido realizada a ontogênese dos estômatos peculiares de $R$. macrophylla, tais estruturas foram denominadas de anormais por serem muito semelhantes àquela descrita por Pant \& Mehra (1965).

As papilas ocorrem na epiderme abaxial de $R$. decipiens e $R$. macrophylla. Segundo Wilkinson (1979) as papilas são constituídas por não mais que uma célula e caracterizadas pela projeção da parede periclinal externa, podendo sua superfície ser ou não ornamentada.

Assim, devido ao fato de $R$. decipiens e $R$. macrophylla receberem reduzida luminosidade e de seu ambiente proporcionar grande disponibilidade de água, poderse-ia concluir que as papilas agiriam como lentes conversoras de estímulos luminosos para o mesofilo, atendendo assim às necessidades do processo fotossintético.

Em ambas as espécies ocorrem numerosos cristais de oxalato de cálcio dos tipos prismáticos, ráfides e drusas, citados também por Lersten (1974), Morretes (1980), Gusmão et al. (1992) e Vieira et al. (1993) para espécies de Rubiaceae.

Franceschi \& Horner Jr. (1980) citam que tais estruturas são sais insolúveis formados a partir do ácido oxálico, sendo posteriormente precipitados em forma de cristais. Os mesmos autores ainda revelam que a síntese dos cristais em plantas pode ser atribuída a necessidade de se remover o oxalato do sistema metabólico, armazenar cálcio, bem como promover o desenvolvimento de defesas contra o ataque de herbívoros.

Os caracteres apresentados por $R$. decipiens e $R$. macrophylla, como folhas de consistência relativamente flexível, coloração verde escura, presença moderada de tecidos mecânicos, rede de nervuras pouco densa, paliçádico pouco desenvolvido e grandes espaços intercelulares no mesofilo correspondem aos citados por Weaver \& Clements (1944), Rizzini (1976), Cutter (1986) e Hart (1988), para plantas de ambiente úmido e sombreado, permitindo classificar $R$. decipiens e $R$. macrophylla como plantas tipicas do interior da floresta.

\section{Referências bibliográficas}

Accorsi, W.R 1947. A ocorrência das células anexas dos estômatos na família Rubiaceae. Anais da E.S.A "Luiz de Queiroz", 4:421-436.

Accorsi, W. R. 1949. Características morfológicas, anatômicas e citológicas da epiderme inferior da folha das Rubiaceae .Lilloa , 16:5-59.

Bahadur, B.; Rajagopal, T. \& Ramayya, N. 1971. Studies on the structural and developmental variation and distribuction of stomata in the Rubiaceae. Bot. J. Linn. Soc., 64:295-310.

Barros, M.A.A. de 1959. Ocorrência das domácias na família Rubiaceae. Anais da E.S.A. "Luiz de Queiroz", 16:331-337. 
Bukatsch, F. 1972. Bemerkungen zur Doppelfarbung Astrablau-Safranin. Mikrokosmos. 61 (8):225.

Combes, R. 1946. La forme des végétaux et le milieu. Paris. Librarie Armand Colin, 222p.

Coutinho, L.M. 1962. Contribuição ao conhecimento da ecologia da mata pluvial tropical. B. Fac. Fil. Ci. Letr: USP Bot., São Paulo, n.18, p. 1-219.

Cutter, E.G. 1986. Anatomia Vegetal. São Paulo, Ed. Roca Ltda., pt.1, 304p.

Dunn, D.B.; Sharma, G.K. \& Campbell, C.C. 1965. Stomatal patterns of dicotyledons and monocotyledons. Am. Midl. Nat., 74:185-195 apud Metcalfe, C.R. \& Chalk, L. 1979. Anatomy of the Dicotyledons. Oxford, Clarendon Press, v.l.

Franceschi, V.R. \& Horner Jr., H.T. 1980. Calcium oxalate crystals in plants. Bot. Rev., 46(4):361-427.

Gomes, D.M.S.; Mantovani, A. \& Vieira, R.C. 1995. Anatomia foliar de Psychotria tenuinervis Müll.Arg. e P. stenocalyx Müll.Arg. (Rubiaceae). Arq. Biol. Tecnol., 38 (I):15-33.

Gusmão,E.D.; Souza,J.P.; Silva, I.M.S. \& Silva, L.B. 1992. Estudo anátomo-morfológico de dicotiledôneas das dunas de Salvador-Bahia. Borreria cymosa Cham. et Schl. e Chiococca brachiata R. et P. (Rubiaceae). Acta Bot. Bras., 6(l):79-98.

Haberlandt, G. 1928. Physiological plant anatomy: London, Macmillan \& Co. Ltd., 777p.

Hart, J.W. 1988. Light and plant grower. London. Unwin Hyman, 204p.

Hickey, L.J. 1974. Classificacion de la arquitectura de las hojas de dicotiledoneas. Bol. Soc. Arg. Bot., l6:(I/2):1-26.

Hughes, A.P. 1959. Effects of the environment of leaf development in Impatiens parviflora DC.. J. Linn. Soc. Bot., 56:161-165.

Isanogle, I.T. 1944. Effects of controlled shoding upon the development of leaf structure in two deciduos tree species. Ecology; 25: 404-413.

Johansen, D. 1940 Plant Microtechnique. New York, McGraw-Hill Book Company Inc., 523.

Lersten, N.R. 1974. Morphology and distribution of colleters and crystals in relation to the toxonomy and bacterial leaf nodule symbiosis of Psychotria (Rubiaceae). Amer.J. Bot, 61(9):973-981.

Mattos, C.C.L.V.; Mattos, M.D.L.V. \& Laroche, R.C. 1976. Aspectos do clima e da flora do Parque Nacional da Tijuca. Bras. Fl., 7-12.

Metcalfe, C.R. \& Chalk, L. 1950. Anatomy of the Dicotyledons. Oxford, Clarendon Press. 1500p.

Morretes, B.L. de. 1980. Contribuição ao conhecimento da anatomia ecológica de plantas do cerrado de Emas-SP e da caatinga amazônica do Km 62 da rodovia BR 174. Tese de Livre Docência, Universidade de São Paulo.

Pant, D.D. \& Mehra, B. 1965. Ontogeny of stomata in some Rubiaceae. Phytomorphology; $15(3): 300-310$. Payne, W.W. 1970. Helicocytic and allelocytic stomata: unrecognised patterns in the dicotyledoneae. Am. J. Bot., 57 (2):140-147.

Reeve, R.M. 1951. Histochemical test for polyphenols in plant tissues. Stain Technol., 26(2):91-96.

Rizzini, C.T. 1976. Tratado de Fitogeografia do Brasil. São Paulo, Ed. de Humanismo, Ciência e Tecnologia Ltda., v.1, 327p.

Robbrecht, E. 1988. Tropical Wood Rubiaceae. Opera Botanica Belgium ,vol 1, 269 p.

Solereder, H. 1908. Systematic anatomy of the Dicotyledons. Oxford, Clarendon Press, 1182p.

Stace, C.A. 1965. Cuticular studies as an aid to plant taxonomy. Bull. Br. Mus.(Nat. Hist. ) Bot., 4(l):1-78.

Steyermark, J.A. 1974. Rubiaceae.In Lasser, T. ed., Flora de Venezuela. Caracas, Edicion Especial del Instituto Botânico, v. 9,2070 p.

Strasburguer, E. 1986. Tratado de Botânica. Barcelona, Ed. Marin, $7^{\mathrm{a}}$ ed., 1098p.

Strittmater, C.G.D 1973. Nueva técnica de diafanización. Bol. Soc. Arg. Bot., 15(1):126-129.

Vieira, R.C. 1986. Diodia radula (Willd et Hoffm.) Cham. et Schlecht. (Rubiaceae). Anatomia foliar. Rev. Brasil. Biol., 46 (3):667-674.

Vieira, R.C. 1986/1988. Tocoyena bullata (Vell.) Mart. (Rubiaceae). Anatomia foliar. Rodriguesia, 64/66 (38/40):33-39.

Vieira, R.C. 1990. Contribuição ao conhecimento da anatomia ecológica de Bauhinia radiata Vell. Dissertação de mestrado, Universidade Federal do Rio de Janeiro. 
Vieira, R.C.; Gomes, D.M.S. \& Ferraz, C.L. 1992. Anatomia foliar de Psychotria nuda Wawra e P. leiocarpa Mart.(Rubiaceae). Hoelnea. 19(1/2):185-195.

Weaver, J.E. \& Clements, F.E. 1944. Ecologia Vegetal. Buenos Aires, Acme Agency Soc. Resp. Ltda., $667 p$.

Wilkinson, H.P. 1979. The plant surface In Metcalfe, C.R. \& Chalk, L. (eds.) Anatomy of the Dicotyledons. Oxford, Clarendon Press, 1:97-165. 